\title{
UMA ARQUEO-GENEALOGIA DA CONFISSÃO: \\ SUBJETIVAÇÃO E FORMAS DE VERIDICÇÃO A PARTIR DOS ÚLTIMOS DITOS E ESCRITOS DE MICHEL FOUCAULT
}

\author{
AN ARCHEO-GENEALOGY OF CONFESSION: SUBJECTIVITY AND FORMS OF VERIDICTION \\ FROM THE LATTER SAID AND WRITINGS OF MICHEL FOUCAULT
}

Sérgio Fernando Maciel Corrêa*

\section{RESUMO}

O artigo procura apresentar uma arqueo-genealogia da confissão a partir dos ditos e escritos de Michel Foucault. Nosso primeiro propósito foi entender as maneiras pelas quais se vinculam sujeito e verdade. Isto posto, o texto empenha-se em analisar a confissão com base na relação entre sujeito e verdade. Dessa forma, o artigo perfaz vários momentos dos últimos quatro anos do trabalho filosófico de Foucault. Ressaltam-se como pontos importantes, nessa trajetória, os vários modos de veridicção e a Parrhesía, noções interpeladas pela ótica da confissão. Para ler os textos de Foucault procuramos nos orientar por uma filosofia que busca a compreensão crítica do presente - o aspecto arqueo-genealógico deste trabalho.

PALAVRAS-CHAVE: Sujeito. Verdade. Confissão. Veridicção. Parrhesía.

\section{ABSTRACT}

The article seeks to present an archeo-genealogy of confession as of pronouncements and writings of Michel Foucault. Our first purpose was to understand the manners in which they are bind subject and truth. That said, the text strives to analyze the confession based on the relation between subject and truth. That way, the article to rebuilds several moments of the last four years Foucault's philosophical work. It is emphasized as important points in this trajectory, the various modes of veridiction and Parrhesia, notions interpellated through the perspective of the confession. To read Foucault's text we pursue us guide by a philosophy which seeks a critical understanding of the present time - the archeo-genealogical aspect of this work

KEY-WORD: Subject. Truth. Confession. Veridiction. Parrhesía.

\footnotetext{
* Professor do Instituto Federal Catarinense, Campus Videira - SC e Doutorando em Filosofia pela Unisinos RS. E-mail: sergio.correa@ifc-videira.edu.br.
} 


\section{INTRODUÇÃO}

Alertamos aos leitores que recortamos textos e entrevistas elaborados a partir de 1981, fase final da atividade intelectual e acadêmica do filósofo francês. No ano de 1981 Michel Foucault vai à Bélgica a convite de Françoise Tulkens, professora da Faculdade de Direito da Universidade Católica de Lovaina para dar uma conferência sobre História do Direito. Em território belga, entre 02 de abril e 20 de maio daquele ano, o Filósofo ministra o curso Mal faire, dire vrai. Fonction de l'aveu en justice. Este artigo tem como escopo fazer uma análise da noção de confissão nos últimos escritos e ditos de Foucault e tem como ponto de partida o curso de 1981 ministrado em Lovaina, cujo tema é a confissão e a sua função na prática da

justiça. É tarefa deste artigo também fazer um estudo de como o sujeito vincula a si mesmo um tipo de verdade que é produto daquilo que Foucault chama de jogos de poder e jogos de verdade. A construção deste texto segue uma orientação metodológica alinhada com a arqueogenealogia foucaultiana.

Neste artigo, então, é preciso dar conta de responder a questões sobre quais condições internas e quais forças coercitivas externas agem em um sujeito que confessa uma verdade que é a verdade de si. Por isso há uma questão política em jogo na confissão: como o indivíduo se relaciona e como aceita se relacionar com o tipo de poder que se exerce sobre ele. Há, de igual maneira, uma questão filosófica no jogo da confissão: saber como os indivíduos estão de fato ligados entre si e por quais formas de veridicção estão envolvidos uns com os outros. Nesse sentido o procedimento arqueo-genealógico praticado por Foucault quer antes demonstrar rupturas históricas levadas a cabo pela ação humana do que analisar a perenidade de conceitos a-históricos.

O curso de 1981 na Bélgica segue a mesma metodologia dos treze cursos oferecidos entre 1971-1984 no Collège de France: ou seja, Foucault tem um manuscrito de apoio e por quase duas horas pronuncia oralmente a um grupo grande de pessoas (geralmente mais de trezentas) fazendo adequações, adendos bibliográficos e reformulações didáticas. Segundo os editores franceses do curso, Fabienne Brion e Bernard E. Harcourt, a edição para publicação desse curso considerou o seguinte: "El texto se estableció sobre la base del manuscrito original del edición de las clases como referencia la grabación audiovisual, que representa la palabra pronunciada públicamente por Foucault”. (FOUCAULT, 2014a, p. 15). 
O filósofo francês, fiel a sua proposta metodológica, quer trazer para os seus ouvintes o tipo de filosofia que ele pratica. Trata-se de uma filosofia que busca pela demarcação histórica das verdades e também pelas rupturas das cadeias de significação que se forjaram e se desconstruíram em torno dos conceitos. Por isso, o objeto da filosofia crítica poderia ser uma criteriosa análise das condições formais e transcendentais que permitiriam a um sujeito pronunciar uma verdade sobre o mundo. O ponto de Foucault, por outro lado, são as tramas históricas que condicionam a verdade e compelem o sujeito a determinadas condições formais de subjetivação. Na primeira aula da conferência Mal faire, dire vrai, o filósofo apresenta o tema geral dessa filosofia crítica: "Y por otra está la que se interroga sobre las formas de veridiccion sobre las diferentes formas de decir veraz"” (FOUCAULT, 2014a, p. 28).

Segue-se então um modo de fazer filosofia que recorre a documentos localizados numa história longínqua, mas que é função da genealogia nos levar a compreender a gama de valores e valorações que constituem a nossa atualidade. Assim, "o primeiro desafio de uma filosofia crítica é mapear tal ruptura epistêmica para, a partir dela, poder entender criticamente a configuração de nosso presente em relação ao modo como tratamos a vida humana" (RUIZ, 2012, p. 43). Aí está, portanto, a orientação que norteará a leitura que faremos dos últimos ditos e escritos de Michel Foucault. Acompanharemos o filósofo nas suas idas e vindas aos textos grecos-romanos e cristãos para compreendermos o papel da confissão nas formas de veridicção e subjetivação dos seres humanos.

\section{As formas de veridicção e a confissão}

Ainda em 1981, Michel Foucault, em uma entrevista, é questionado sobre o papel da confissão na construção de sua obra e em que lugar ela estaria situada. Em duas páginas transcritas, o filósofo prontamente faz uma análise geral dos seus ditos e escritos. Na síntese ele destaca o problema da verdade e de como ela toca as grandes temáticas com as quais lidou. Nesse sentido, seu objetivo é apreciar como a verdade aparece e se torna um problema que transpassa a questão da loucura. A loucura era um dilema que exigia uma verdade verbalizada, inclusive do louco. São pontos que ele tratou em A história da loucura. Do mesmo modo, há uma tentativa de apresentar como a verdade está implicada em uma história da linguagem e das ciências naturais como é, por exemplo, o assunto de As palavras $e$ as coisas. 
Segundo o filósofo, quando ele trata do criminoso, das prisões e das instituições jurídicas, há uma busca pela verdade, não acerca da responsabilidade jurídica do criminoso, mas um interrogatório é dirigido à verdade do "eu" do criminoso. Tais questões são tratadas, por exemplo, em Vigiar e punir. No que concerne à sexualidade, segundo o filósofo, também se formulam questões que implicam, na modernidade, a busca de uma verdade antropológica do desejo sexual. O pensador então conclui sua análise: “A partir dos séculos XVI-XVII, estamos em contato com três séries: exclusão-loucura-verdade, correção-prisão-verdade, comportamento sexual-confissão-verdade" (FOUCAULT, 2014b, p. 332).

É certo que a problematização da verdade está posta em todos os casos, seja ele o da loucura, o da sexualidade e o da prisão. O método arqueo-genealógico parte da premissa de que a verdade é uma prática e, sobretudo, uma prática histórica. Por isso o ponto a ser perscrutado não é a da validade de um argumento, nem a deliberação sobre a falsidade ou validade de uma sentença científica e nem mesmo sobre a coerência e a rigorosidade de uma interpretação de um texto clássico, por exemplo. Esses campos pertencem a outras formas metodológicas, como observa Castor Ruiz:

A genealogia explora outras dimensões da verdade, outros campos onde a verdade se valida como tal, além da sua coerência lógica ou do sentido hermenêutico. A genealogia, enquanto método filosófico, é complementar e não disjuntiva ou excludente de outros métodos (fenomenologia, hermenêutica, dialética, pragmática...) (RUIZ, 2013, p 47).

Uma arqueo-genealogia da confissão requer que se articule poder, verdade e formas de veridicção para que haja uma compreensão coerente das formas de verdade que o sujeito valida sobre si mesmo. Nesse sentido, a confissão vincula o sujeito ao que ele disse de si mesmo e ao mesmo tempo o qualifica frente ao outro em respeito ao que pronunciou sobre si mesmo. Em virtude da vinculação entre sujeito e verdade, Candiotto escreve: “A perspectiva do genealogista-arqueólogo é que, no fundo, a verdade é ininteligível sem uma obrigação de verdade, sem o éngagement do indivíduo, sem seu assujeitamento consentido" (CANDIOTTO, 2010, p. 68).

Com alguma certeza é ponto passivo que a verdade que emana da confissão não é o afloramento de uma essência escondida que o sujeito, por um esforço racional, deslinda. "En la confesión, quién habla se obliga a ser lo que dice ser, se obliga a ser quien ha hecho tal o cual cosa, quien experimenta tal o cual sentimiento; y se obliga porque es verdad" 
Artigo: Uma arqueo-genealogia da confissão: subjetivação e formas de veridicção a partir dos últimos ditos e escritos de Michel Foucault

(FOUCAULT, 2014a, p. 26). Por consequência a confissão assume o status linguístico da verbalização de um "ato de verdade do eu".

Assim a arque-genealogia da confissão encontra uma reivindicação por demais antiga: a busca pela verdade do eu. Nesse sentido, os modos de viver se encontram em obrigação para com a verdade. A determinação em relação à verdade compele o sujeito ao reconhecimento das ações que pratica e, claro, ao conhecimento de si mesmo. Todavia, há um segundo elemento imprescindível para se completar o ciclo da confissão: a obrigação de narrar, descrever, pormenorizar, tornar clara para um interlocutor a verdade de si mesmo e das ações praticadas.

Para Michel Foucault é evidente que essa noção de confissão existe desde a antiguidade. Porém o estatuto da confissão é bem diferente na antiguidade daquele praticado dentro do cristianismo. Nos antigos, segundo o autor, a confissão era uma ferramenta, uma técnica que envolvia o discipulado: um diretor espiritual e um discípulo que buscava orientação para viver uma vida correta. Tratava-se de uma prática que não envolvia exigências de uma verdade do eu. A verdade a ser procurada não era na interioridade do sujeito, mas transparecia nas suas ações que concorriam ou não para uma vida correta. Somente no cristianismo a confissão passou a ser uma técnica de si, no sentido da busca por uma verdade interiorizada do sujeito. A passagem da entrevista de 1981 é clara:

\footnotetext{
Nos autores clássicos, a condução do guia visava a um objetivo específico: a vida íntegra ou a saúde total. Uma vez atingido este objetivo, a direção se interrompia e supunha-se que o guia já estava mais avançado no caminho que levava ao objetivo. O monasticismo muda radicalmente essa situação. É preciso confessar não apenas os deslizes cometidos, mas absolutamente tudo, até os pensamentos mais íntimos. Há que se formulá-los. (FOUCAULT, 2014b, p. 334).
}

Neste momento podemos questionar qual o papel e qual a posição que o problema da confissão assume no corpo da obra de Michel Foucault. Como foi dito acima, o tema da confissão está na órbita de outro problema de grandeza maior: a questão da verdade. Por certo, o tema da confissão entra como uma ferramenta necessária ao propósito genealógico do filósofo francês. Em acordo com tal hipótese, na mesma entrevista de 1981 está dito: "Incessantemente eu vou ao encontro da confissão e hesito, seja em escrever uma história da confissão como uma espécie de técnica, seja em tratar essa questão no quadro dos estudos dos diferentes domínios nos quais ela parece desempenhar um papel no domínio da sexualidade, e o da psiquiatria" (FOUCAULT, 2014b, p. 333-334). 
Sob esse ponto de vista, ainda em 1981 na conferência Mal faire, dire vrai, Michel Foucault delimita para seu público os temas a serem tratados. O ponto elementar a ser abordado são as interlocuções entre o "dizer verdadeiro" e a atividade do "dizer justo", isto é: la actividad de veridicción y la actividad de jurisdicción. (FOUCAULT, 2014a, p. 39). De acordo com a hipótese de que a confissão é um instrumento para tratar do problema da verdade, o filósofo destaca que a prática da confissão não é só tema emblemático no âmbito do direito. Mas também o problema da confissão é item controverso para a formação moral do sujeito, assim como para as práticas religiosas.

Em 1982, no curso ministrado no Collège de France, sob o título de L'Herméneutique $d u$ sujet o tema da confissão aparece em primeiro lugar como um elemento importante para a questão da formação moral da ascese filosófica entre os antigos. A ascese é posta por Foucault na aula de três de março de 1982 como uma ferramenta de que o sujeito precisava ser dotado para não ser envolvido pelos acontecimentos da vida. Seria uma espécie de armadura moral com a qual o sujeito se armaria por meio de discursos sobre si mesmo que necessariamente o ligariam à verdade.

\footnotetext{
Em suma, poderíamos dizer que - e foi nisto, creio, que me detive na última vez - a ascese é o que permite, de um lado, adquirir os discursos verdadeiros, dos quais se tem necessidade em todas as circunstâncias, acontecimentos e peripécias da vida, a fim de se estabelecer uma relação adequada, plena e acabada consigo mesmo; de outro lado, e ao mesmo tempo, a ascese é o que permite fazer de si mesmo o sujeito destes discursos verdadeiros, é o que permite fazer de si mesmo O sujeito que diz a verdade e que, por esta enunciação da verdade, encontra-se transfigurado, e transfigurado precisamente pelo fato de dizer a verdade. (FOUCAULT, 2010, p. 296).
}

Por certo, a ascese do tipo moral-filosófica implica em uma subjetivação do "eu" no discurso verdadeiro. Nesse sentido o sujeito é quem sustenta por ele mesmo o discurso verdadeiro e ao mesmo tempo é quem enuncia a si mesmo no próprio discurso. Em suma, o conteúdo do silogismo é o si mesmo. Por envolver uma relação de discipulado, Candiotto registra: "A constituição do sujeito pela enunciação de sua própria verdade configura o efeito de uma relação de poder e por isso se trata de subjetivação sujeitada. $\mathrm{O}$ vínculo entre o sujeito e sua verdade é estabelecido em virtude dos mecanismos do saber-poder" (CANDIOTTO, 2007, p. 08).

Na mesma linha de raciocínio, Michel Foucault destaca que bem outra é a função da confissão praticada no âmbito do cristianismo, da ascese cristã. Na prática da confissão do tipo cristã está em jogo não o fortalecimento moral do sujeito, mas sim a renúncia de si mesmo. 
Ao passo que a ascese cristã, por sua vez, terá sem dúvida uma função completamente diferente: função, é claro, de renúncia a si. Entretanto, no caminho em direção à renúncia de si, ela dará lugar a um momento particularmente importante que é o momento da confissão, isto é, o momento em que o sujeito objetiva-se a si mesmo em um discurso verdadeiro. (FOUCAULT, 2010, p. 296).

A fim de que a salvação seja obtida por um ato de renúncia de si é que a confissão foi inscrita nas práticas cristãs. Mais uma vez a confissão é uma importante ferramenta na transformação do sujeito por si mesmo. Em outras palavras, a obrigação do dizer verdadeiro, no âmbito da pastoral cristã, é um capítulo importante e de relevância indispensável para a construção de uma arqueo-genealogia das junções e disjunções entre sujeito e verdade. Foucault destaca aos seus ouvintes em 03 de março de 1982: "Na história do Ocidente, quem é dirigido e quem é conduzido só passará a ter o direito de falar no interior da obrigação do dizer-verdadeiro sobre si mesmo, isto é, na obrigação da confissão" (FOUCAULT, 2010, p. $325)$.

Nesse contexto grego-romano, a confissão tem um caráter relacional. Há sempre uma relação vertical entre mestre-discípulo e uma relação horizontal que ocorre no âmbito da escola filosófica dos discípulos entre si. Para que haja a dimensão relacional entre alteridades é preciso Parrhesía, que Foucault bem define:

\footnotetext{
Etimologicamente, parrhesía é o fato de tudo dizer (franqueza, abertura de coração, abertura de palavra, abertura de linguagem, liberdade de palavra). Os latinos traduzem geralmente parrhesía por libertas. E a abertura que faz com que se diga, com que se diga o que se tem a dizer, com que se diga o que se tem vontade de dizer, com que se diga o que se pensa dever dizer porque é necessário, porque é útil, porque é verdadeiro. (FOUCAULT, 2010, p. 327).
}

Falar o que pensa, falar para abrir o coração e enunciar as faltas cometidas, verbalizar as fraquezas que sente na conduta de discípulo e que ainda se sente exposto: eis a Parrhesía. Trata-se do modo de ser do discipulado no recinto da escola filosófica a qual Foucault compara com a prática da confissão dentro do cristianismo primitivo: "Uma prática da confissão inteiramente diferente das práticas rituais, religiosas que, depois de se ter cometido um furto, um delito, um crime, consistiam efetivamente em ir ao templo e depositar uma estela ou fazer uma oferenda" (FOUCAULT, 2010, p. 350).

Além disso, nessa confissão há um engajamento daquele que fala em ser aquilo que enuncia. Em suma, há uma obrigação de ser aquele pecador que cometeu tal e tal pecado, experimentou tais e tais sensações ao pecar. O sujeito que confessa se compromete em ser um pecador na e pela sua confissão. Candiotto (2010, pp. 69-71), afirma que só há confissão na 
relação de poder em que aquele que confessa se submete a ela. Não só a confissão implica relações de poder, mas também a prática da confissão efetiva e legitima determinadas práticas de poder, como descreve Ruiz: "A imbricação do poder e da verdade repercute sobre as formas de subjetivação. Os sujeitos se subjetivam a partir das verdades aceitas que orientam seu modo de agir, o qual, por sua vez, constitui o modo de subjetivar-se" (RUIZ, 2013, p. 47). Nessa confissão do tipo cristã, portanto, o sujeito que declara uma verdade é, ele mesmo o referente daquilo que declarou.

\section{A parrhesía como prática da confissão}

Em 1983 Michel Foucault vai aos Estados Unidos e nas dependências da Universidade da Califórnia - UC e no Campus Berkeley pronuncia, em língua inglesa, o Curso: Discourse and truth: the problematization of parrhesia ${ }^{1}$. O conteúdo das seis conferências que compõem o curso é explícito: trata-se de uma genealogia da noção grega de Parrhesía, marcando seus desmembramentos em vários segmentos. Na quarta conferência do curso, cujo título é The practices of parrhesia, o filósofo francês aprecia como a parrhesía aparece nos diálogos socráticos em forma de confissão. Para ele é muito diferente o jogo parrhesiástico em uma assembleia política na qual o foco principal é a persuasão, daquela praticada por Sócrates com seus interlocutores. Nos diálogos socráticos o interlocutor precisa dar um relato de si . "Here, the listener is led by the Socratic logos into "giving an account" - didonai logon - of himself." (FOUCAULT, 1999, p. 37).

Alertamos que esse relato de si, no socratismo, não é análogo ao do tipo cristão que envolve um exame de consciência, portanto, uma interiorização que, em seguida, transparece em forma de relato autobiográfico ou mesmo uma confissão sincera e arrependida das próprias faltas. Sócrates quer que o seu interlocutor seja corajoso o suficiente para demonstrar que existe uma relação entre o discurso racional, o Lógos, que o sujeito é capaz de usar, e o modo como vive - Bios. Nessa linha Michel Foucault é bastante claro ao tratar da Parrhesía dentro dos diálogos Socráticos: "Socrates is inquiring into the way that logos gives form to a person's style of life; for he is interested in discovering whether there is a harmonic relation between the two" (FOUCAULT, 1999, p. 37).

\footnotetext{
${ }^{1}$ O Curso está disponível em formato .pdf e também estão disponíveis os áudios originais que podem também ser acessados livremente em: http://www.lib.berkeley.edu/MRC/foucault/parrhesia.html.
} 
Por certo as colocações do curso de novembro de 1983, no campus Berkeley da UC, refletirão nas preleções dadas no último curso ministrado por Foucault no Collège de France a partir de fevereiro de 1984 sob o título: Le Gouvernement de soi et des autres: le courage de la vérité. Este curso teve seu início em fevereiro de 1984 devido ao agravamento do estado de saúde de Foucault, diferentemente dos outros doze cursos que sempre começavam na primeira ou segunda semana de janeiro. Em certo sentido o conteúdo do curso é continuação do anterior, Le Gouvernement de soi et des autres, de 1983, que tratou da problematização do dizer-verdadeiro nos campos da ética e da política.

Na segunda parte da aula de 22 de fevereiro de 1984, o filósofo se propõe a discorrer sobre a Parrhesía em seu momento socrático. Esta Parrhesía acontece por meio do método praticado pelo filósofo ateniense. Sócrates vai perquirir o seu interlocutor ao extremo, correndo inclusive risco de sofrer violência. $\mathrm{Na}$ indagação socrática o próprio método conduz o interlocutor a dar explicações acerca de si mesmo, do estilo de vida que leva. Trata-se, como foi dito acima, de colocar a Bios no âmbito do Lógos. Como está dito:

Pois bem - é o signo sob o qual se coloca toda a parresía socrática e sua veridicção -, qualquer que seja o sujeito que se aborde com Sócrates é necessário (anágke) que as coisas ocorram da seguinte maneira: Sócrates não desistirá enquanto seu interlocutor não for levado (periagómenon: levado como que pela mão, passeando) até o ponto em que pode prestar contas de si mesmo. (FOUCAULT, 2011, p. 125).

O tipo de confissão para a qual o interlocutor de Sócrates é conduzido é uma espécie de prova, cujo critério, a pedra de toque, é o próprio Lógos. Em outras palavras, o sujeito é capaz de dar razão a si mesmo, ao modo como vive. A forma que se está dando a existência, a vida, a Bios, é capaz de resistir ao crivo da razão? Não se trata de um exame de consciência, mas essa confissão ao estilo de prova é para toda a avida. Não é a confissão de um crime como no âmbito jurídico-penal; não é a confissão dos pecados como nas práticas religiosas; não é a confissão do louco que se reconhece como tal no domínio do saber-poder da medicina. A exigência aqui é outra: busca-se a harmonização entre vida (Bios) e discurso (Logos). A fala franca (Parrhesía) se combina a partir de uma estetização da própria existência. Nesse caso temos:

\footnotetext{
A emergência da vida, do modo de vida como objeto da parresía e do discurso socráticos, vida em relação à qual é preciso exercer uma operação que será uma operação de prova, de pôr à prova, de triagem. É preciso submeter a vida a uma pedra de toque para separar exatamente o que é bom do que não é bom no que se faz, no que se é, na maneira de viver. (FOUCAULT, 2011, p. 127).
} 
Posteriormente, no cristianismo, esta maneira de pôr à prova a própria vida com relação à racionalidade vai se transfigurar em coragem de verdade perante Deus. O assunto é discutido por Michel Foucault nas últimas palavras da aula derradeira de 28 de março de 1984 no Collège de France. Na parte final dessa aula, o filósofo tem como propósito discorrer acerca do modo como a Parrhesía aparece nos primeiros textos cristãos. Duas coisas são marcantes nesta arqueo-genealogia da Parrhesía: a confissão corajosa que implica abertura de coração para com Deus. Por outro lado, há uma desconfiança em relação a si mesmo, pois o que está em jogo é sempre um temor em relação aos propósitos de Deus que tem uma vontade própria e conhece as vontades carnais do crente.

Por certo, o tema da verdadeira vida, do estilo de vida que se pode pôr à prova, da comunicação de uma verdade de si está presente nesse tipo de parrhesía. A fim de ilustrar tal hipótese, está dito: "Vocês vão encontrar a ideia de uma parresía como parresía de vis-a-vis, de face-a-face com Deus. Nesse estado primitivo da relação da humanidade com Deus: abertura de coração, presença imediata, comunicação entre a alma e Deus” (FOUCAULT, 2011, p. 292).

Porém, o princípio de desconfiança em relação a si, de temor e tremor em relação a Deus que abordamos antes implicará ainda mais uma perscrutação da verdade de si mesmo, da purificação da alma pecadora, da reestruturação da relação para com Deus. Neste sentido, somente após o sujeito ter decifrado a si e ter tido a coragem de confessar é que a alma é purificada e a relação com Deus é retomada. "Só se alcançará a verdadeira vida com a prévia condição de ter praticado sobre si essa decifração da verdade" (FOUCAULT, 2011, p. 296). Portanto, o acesso à verdadeira vida só acontece por meio da confissão que "confessa" antes uma verdade da vida.

\section{CONSIDERAÇÕES FINAIS}

É possível compreender que o tema da confissão perpassa toda a obra de Michel Foucault. Mas é, sobretudo, nos seus ditos e escritos finais que a relação entre prática de si como prática da verdade vai brotar de uma relação de poder em virtude da qual o sujeito colocará a si mesmo como premissa de um silogismo verdadeiro. Desde a introdução deste trabalho nosso objetivo foi o de marcar, do ponto de vista de uma subjetividade, sob tais e quais condições o sujeito formula na linguagem uma verdade sobre si mesmo. Servimo-nos da arqueo-genealogia foucaultiana para cumprirmos os nossos objetivos que tendiam para uma 
filosofia crítica cujo objeto e característica maior são a percepção do nosso presente e o modo como a existência humana é tratada.

$\mathrm{Na}$ primeira seção deste texto tratamos de verificar as disposições em que se relacionam as formas de veridicção e confissão. Em síntese, versamos sobre várias maneiras como se apresenta o dever que se impõe aos sujeitos de dizerem a verdade sobre eles mesmos. Em suma, qual é o modelo de relação que existe entre sujeito e verdade. Ante isso, a filosofia crítica foucaultiana quer perscrutar quais razões agregam sujeito e verdade. No entanto, salientamos que não se trata de um sujeito universal que pode conhecer uma verdade geral e que estaria preparado para fazer um relato acerca de verdades lógicas, ou até mesmo enunciar a validade epistêmica de uma sentença qualquer.

A arqueo-genealogia de Foucault certifica que a confissão é um tema-problema desde a antiguidade grega. Se entre os gregos o problema da verdade de si girava em torno das formas de viver dentro das comunidades filosóficas, no cristianismo a confissão será uma conduta a ser praticada pelo indivíduo ao longo da vida. No cristianismo o sujeito inquere a si mesmo através de um constate exame de consciência que de certa forma tranquiliza o sujeito na relação com ele mesmo e o impele, pela ascese, a ser de outro modo. Por causa dessas questões talvez Nietzsche tenha posto na boca do Sábio que interpela Zaratustra sobre a necessidade do exame de consciência para dormir bem. No discurso Das cátedras da virtude, o sábio afirma para Zaratustra que para bem dormir é preciso dez vezes durante o dia superarse a si mesmo, dez vezes é preciso reconciliar-se consigo mesmo, dez verdades é preciso encontrar e antes de dormir é necessário dar conta para si mesmo dessas práticas durante a vigia diurna. Por fim, concluiu o interlocutor de Zaratustra:

\footnotetext{
Assim transcorre o dia para o virtuoso. E, quando vem a noite, eu bem me guardo de chamar o sono! Pois o sono que é senhor das virtudes não quer ser chamado. Em vez disso, penso no que fiz durante o dia. Ruminando me pergunto, paciente como uma vaca: quais foram afinal tuas dez superações? E quais foram as dez conciliações e as dez verdades, e as dez risadas com que se regalou meu coração? Isso refletindo, e acalentado por quarenta pensamentos, assalta-me de repente o sono, o não chamado, o senhor das virtudes. (NIETZSCHE, 2011, p. 29-31).
}

Não só isso, mas outro aspecto importante que serviu aos nossos propósitos foi associação entre Parrhesía e confissão, matéria abordada na segunda seção deste artigo. Essa forma de Parrhesía, quando da sua relação com a confissão, surge com Sócrates. O método socrático intenta direcionar o sujeito a colocar a si mesmo (Bios) num discurso racional (Lógos). Portanto, a confissão aqui é uma prova a que o sujeito se submete com o intuito de 
dar razão a si mesmo e ao modo como vive. Em suma é necessário sujeitar a vida à uma pedra de toque para discriminar o bom do que não é no que se faz, no que se é e no modo de viver. Assim cremos que na proveniência da confissão estão imbricadas essas questões que nos remetem à antiguidade grega, transpassando toda uma prática de confissão dentro do cristianismo.

\section{REFERÊNCIAS}

FOUCAULT, Michael. A hermenêutica do sujeito: curso dado no Collège de France (19811982). Tradução Márcio Alves da Fonseca e Salma Tannus Muchail. 3. ed. São Paulo: Martins Fontes, 2010.

FOUCAULT, Michael. A coragem da verdade: o governo de si e dos outros II: curso no Collège de France (1983-1984). Tradução Eduardo Brandão. São Paulo: Martins Fontes, 2011.

FOUCAULT, Michael. Obrar mal, decir la verdad: función de la confesión en la justicia. Curso de Lovaina. Tradução Horacio Pons. Buenos Aires: Siglo Veintiuno Editores, 2014a.

FOUCAULT, Michael. Entrevista com Michel Foucault. In.: Ditos e escritos Vol. I: problematização do sujeito: psicologia, psiquiatria e psicanálise. 3. ed. Rio de Janeiro: Forense, 2014b.

FOUCAULT, Michael. The Practice of Parrhesia. In: Discourse and truth: the problematization of parrhesia. edited by Joseph Pearson. Digital Archive: Foucault info, 1999.

CANDIOTTO, Cesar. Foucault e a crítica da verdade. Curitiba: Champangnat, 2010.

CANDIOTTO, Cesar. Verdade, confissão e desejo em Foucault. In: Revista observaciones filosóficas. Valparaíso (Chile), vol. 1, nº4, pp. 1-10, 2007.

NIETZSCHE, Friedrich. Assim falou Zaratustra: um livro para todo e para ninguém. Tradução Paulo César de Souza. São Paulo: Companhia das Letras, 2011.

RUIZ, Castor Bartolomé. Objetivação e governo da vida humana. Rupturas arqueogenealógicas e filosofia crítica. Revista IHU On-Line, ed. 389, São Leopoldo: Instituto Humanitas Unisinos, 2012, p. 42-48.

RUIZ, Castor Bartolomé. A verdade das práticas e a verdade como prática. Revista IHU OnLine, ed. 432, São Leopoldo: Instituto Humanitas Unisinos, 2013, p. 46-53. 